\title{
Time-Varying Volatility Connectedness of Asset Markets: Evidence from Century-Long Data
}

\author{
Ting Huang \\ Department of Finance and Institute of Economics, Jinan University, Guangzhou, China \\ Email: m15626091094@163.com
}

How to cite this paper: Huang, T. (2020). Time-Varying Volatility Connectedness of Asset Markets: Evidence from Century-Long Data. American Journal of Industrial and Business Management, 10, 411-420. https://doi.org/10.4236/ajibm.2020.102027

Received: January 31, 2020

Accepted: February 17, 2020

Published: February 20, 2020

Copyright $\odot 2020$ by author(s) and Scientific Research Publishing Inc. This work is licensed under the Creative Commons Attribution International License (CC BY 4.0).

http://creativecommons.org/licenses/by/4.0/

\section{(c) (i) Open Access}

\begin{abstract}
We employ the framework of (Antonakakis \& Gabauer, 2017) to study the nature of the volatility transmission among stocks, bonds, oil and gold over the past 100 years (1915-2015). The results indicate that asset market linkages and the role of volatility transmitter or receiver vary considerably over time. We observe a stronger net volatility transmitter of crude oil during the past 100 years and gold acts as a net volatility transmitter only before the 1970 s. Moreover, stock is generally the most connected asset with receiving the majority of volatility shocks from all other assets while switches to a volatility transmitter since 2008. In addition, the findings show that the significant changes in the volatility spillovers among asset markets are closely related to the heightened uncertain economic and financial conditions in a long-term perspective.
\end{abstract}

\section{Keywords}

Asset Market Linkage, Connectedness, Volatility Spillover, Time-Varying Volatility

\section{Introduction}

It is well known there exists substantial time variation in the linkages as well as volatility spillovers among asset markets in a long-term perspective. Characterizing the nature of time variation in their relationships across different assets has important implications for understanding the financial system and may have practical applications in allocation decision and risk management (Connolly, Stivers, \& Sun, 2005; Yang, Zhou, \& Wang, 2009). In this paper, we study dynamic volatility spillovers among stocks, bonds, oil and gold with a special interest in periods with structural changes in their relationships over the past 100 years. We extend prior work by identifying dynamic volatility connectedness 
across major asset markets and underlying causes of their time variation. Our motivation follows from recent literature on cross-market relationship (e.g., Fleming, Kirby, \& Ostdiek, 1998; Cappiello, Engle, \& Sheppard, 2006; Diebold \& Yilmaz, 2012; Baruník, Kočenda, \& Vácha, 2016; Yang \& Zhou, 2016; Andrada-Félix, Fernandez-Perez, \& Sosvilla-Rivero, 2018; Zaremba, Kambouris, \& Karathanasopoulos, 2019) and the underlying economic and financial conditions (Hartmann, Straetmans, \& De Vries, 2004; Connolly Stivers, \& Sun, 2005; Büyükşahin \& Robe, 2014; Chen, 2018).

Although there is a growing body of empirical literature on asset market linkages, particularly on pairwise relationship in recent decades (e.g., Phylaktis \& Ravazzolo, 2005; Kilian \& Park, 2009; Basher, Haug, \& Sadorsky, 2012; Grobys, 2015; Foroni, Guérin, \& Marcellino, 2017), relatively few studies have explored the long history of dynamic volatility spillovers as well as their corresponding transmission pattern (Yang, Zhou, \& Wang, 2009). In a long-term perspective, a context of heightened uncertain macroeconomic or financial environments (such as economic/energy crises, international policy transformation, etc.) tends to lead to higher financial market uncertainty that may relate to more frequent revisions in investors' assessment of different asset risks and thus impact the cross-asset relationship associated with hedging against risks.

In this study, we revisit the issue of time-varying connectedness and volatility spillovers among stocks, bonds, gold and oil from 1915 to 2015. We focus on two empirical questions. The first empirical question is to investigate how major asset markets connect with others over the past 100 years. This investigation further evaluates which asset may act as a volatility spillover receiver (or transmitter) in a historical perspective. Our second question is to link the time variation in volatility connectedness to the underlying economic conditions in a long-term perspective. During periods of highly uncertain economic conditions, the substantial increases in financial volatility may result in changes in volatility transmission as well as cross-asset connectedness over time.

The paper adds to existing literature along the following dimensions: First, this study employs the century-long historical data (1915-2015) that covers 18 expansions and 18 recessions. This unique dataset allows us to understand different patterns of time-varying connectedness and volatility spillovers across assets over a large number of business cycles. In contrast, previous studies generally focus on a relatively few cycles in recent decades. The use of century-long financial data is very important in characterizing the significant transitions of volatility connectedness. Second, we adopt a full-fledged time-varying parameter vector autoregressive (TVP-VAR) model developed by (Antonakakis \& Gabauer, 2017) to capture connectedness and volatility spillovers across assets. Contrary to the rolling window estimation of the (Diebold \& Yilmaz, 2012) model, this framework is advantageous in being less sensitive to the rolling-window size setting and extreme outliers as well as no loss of observations when measuring connectedness. Finally, the paper attempts to link the dynamics of volatility connected- 
ness to the underlying economic/financial conditions in a long-horizon perspective. This provides insight into uncovering the role of extreme events, such as international policy transformation, economic or energy crises, in determining the dynamic nature of volatility transmission.

This paper is organized as follows. Section 2 outlines the empirical methodology. Section 3 presents the data description and empirical results. Finally, Section 4 concludes.

\section{Methodology}

To explore time-varying volatility spillover mechanism among various assets, we employ the methodology proposed by (Antonakakis \& Gabauer, 2017). In particular, the TVP-VAR model can be written as follows:

$$
\begin{gathered}
Y_{t}=\beta_{t} Y_{t-1}+\varepsilon_{t}, \quad \varepsilon_{t} \mid F_{t-1} \sim N\left(0, S_{t}\right) \\
\beta_{t}=\beta_{t-1}+v_{t}, \quad v_{t} \mid F_{t-1} \sim N\left(0, R_{t}\right) \\
Y_{t}=A_{t} \varepsilon_{t-1}+\varepsilon_{t}
\end{gathered}
$$

where $Y_{t}, \varepsilon_{t}$ and $v_{t}$ are $N \times 1$ vector and $\varepsilon_{t}$ is an $N \times 1$ dimensional error disturbance vector. $\beta_{t}$ is an $N \times N$ matrices of dynamic coefficient while $S_{t}$ and $R_{t}$ are time-varying variance-covariance matrix. (Diebold \& Yilmaz, 2012) introduce time-varying coefficient of vector moving average (VMA) as the fundamental dynamic connectedness index by combining generalized impulse response function (GIRF) and generalized forecast error variance decomposition (GFEVD) proposed by (Koop, Pesaran, \& Potter, 1996) and (Pesaran \& Shin, 1998) respectively. Following the Wold theorem, the VAR is thus transformed to its VMA form as:

$$
\begin{gathered}
Y_{t}=\beta_{t} Y_{t-1}+\varepsilon_{t} \\
Y_{t}=A_{t} \varepsilon_{t} \\
A_{0, t}=I \\
A_{i, t}=\beta_{1, t} A_{i-1, t}+\cdots+\beta_{p, t} A_{i-p, t}
\end{gathered}
$$

where $\beta_{t}$ and $A_{t}$ are $N \times N$ dimensional parameter matrices.

We focus on h-step error variance in forecasting variable $i$ that results from shocks on variable $j$. It can be presented as follows:

$$
\begin{gathered}
\tilde{\varphi}_{i j, t}^{g}(h)=\frac{\sum_{t=1}^{h-1} \psi_{i j, t}^{2, g}}{\sum_{i=1}^{N} \sum_{t=1}^{h-1} \psi_{i j, t}^{2, g}} \\
\psi_{i j, t}^{2, g}=S_{i j}^{-\frac{1}{2}} A_{h, t} \sum_{t} \varepsilon_{i j, t} \\
\sum_{t=1}^{h-1} \tilde{\varphi}_{i j, t}^{g}(h)=1 \text { and } \sum_{1, j=1}^{N} \tilde{\varphi}_{1, j=1}^{N}(h)=N
\end{gathered}
$$

where $\tilde{\varphi}_{i j, t}^{g}(h)$ is h-step ahead GFEVD, and $\Sigma_{t}$ is the covariance matrix for error $\varepsilon_{i j, t}$.

The total directional volatility spillover connectedness of variable $i$ to all oth- 
ers $j$ can be defined as:

$$
C_{i \rightarrow j, t}^{g}(h)=\frac{\sum_{j=1, i \neq j}^{N} \tilde{\varphi}_{j i, t}^{g}(h)}{\sum_{j=1}^{N} \tilde{\varphi}_{j i, t}^{g}(h)} \times 100
$$

Similarly, the total directional volatility spillover connectedness from variables $j$ to variable $i$ is defined as:

$$
C_{i \leftarrow j, t}^{g}(h)=\frac{\sum_{j=1, i \neq j}^{N} \tilde{\varphi}_{j i, t}^{g}(h)}{\sum_{j=1}^{N} \tilde{\varphi}_{j i, t}^{g}(h)} \times 100
$$

Thus, the net directional volatility connectedness can be defined as follows:

$$
C_{i, t}^{g}(h)=C_{i \rightarrow j, t}^{g}(h)-C_{i \leftarrow j, t}^{g}(h)
$$

A negative net directional volatility connectedness $\left(C_{i, t}^{g}(h)<0\right)$ indicates that variable $i$ is driven by other variables of the network, while a positive one $\left(C_{i, t}^{g}(h)>0\right)$ indicates that variable $i$ impacts the network more than being impacted by that.

Finally, the net directional connectedness is adjusted to measure the bidirectional relationship by computing the net pairwise directional connectedness (NPDC).

$$
N P D C_{i j}(h)=\frac{\tilde{\varphi}_{j i, t}^{g}(h)-\tilde{\varphi}_{i j, t}^{g}(h)}{N} \times 100
$$

\section{Empirical Results}

The dataset consists of monthly price indices of the U.S. stock market (S\&P 500), ten-year government bonds, gold and crude oil from January 1915 to December 2015. We use first log-difference $r_{t}=\ln \left(y_{t}\right)-\ln \left(y_{t-1}\right)$ to obtain monthly returns. Monthly data on the S\&P 500 price indices and bond return indices are taken from Robert Shiller's publication Irrational Exuberancel. We collect the gold prices in contemporary dollars from Macro Trends Database $e^{2}$ and the prices of crude oil from Global Financial Data ${ }^{3}$.

In Table 1, we report the static volatility connectedness for the assets obtained through generalized variance decomposition in TVP-VAR model. As shown in the table, the largest net spillover comes from crude oil (20.8\%), indicating that oil market plays a critical role in the volatility of the entire financial markets. Interestingly, while gold is a volatility transmitter $(8.3 \%)$ in a long-term perspective, stock market acts as a volatility receiver $(-42.4 \%)$, indicating that it is mostly driven by external influences as a whole. Further, the volatility connectedness from all other assets to stocks is relatively high, ranging from $17.8 \%$ to $20.4 \%$ (see Row 1 ).

\footnotetext{
${ }^{1}$ Shiller, Robert J. Irrational exuberance. Princeton University Press, 2000. Online dataset: http://www.econ.yale.edu/ shiller/data.htm.

${ }^{2}$ Detail explanation of the variables and extensive discussion of the system level data can be found at https://www.macrotrends.net/. Real datasets are adjusted for inflation using the headline Consumer Price Index (CPI) with the current month as the base.

${ }^{3}$ Online dataset: http://www.globalfinancialdata.com/. GFD specializes in providing financial and economical Data that extends beyond what traditional data vendors provide.
} 
Table 1. Volatility connectedness of asset markets.

\begin{tabular}{cccccc}
\hline & Stock & Bond & Oil & Gold & FROM \\
\hline Stock & 43.9 & 17.9 & 20.4 & 17.8 & 56.1 \\
Bond & 4.7 & 40.2 & 32.1 & 23.0 & 59.8 \\
Oil & 4.7 & 30.3 & 41.9 & 23.1 & 58.1 \\
Gold & 4.4 & 24.8 & 26.4 & 44.5 & 55.5 \\
Contribution to others & 13.7 & 73.0 & 78.9 & 63.8 & \\
Contribution including own & 57.6 & 113.2 & 120.8 & 108.3 & \\
Net spillovers & -42.4 & 13.2 & 20.8 & 8.3 & 57.4 \\
\hline
\end{tabular}

In contrast, the volatility connectedness from stocks to all other assets is less than $5 \%$ (see Column 1). The netcontribution shows the transmission of volatility from all other assets to stocks. This is expected as oil, gold and bonds are all important factors, which are heavily weighted by stock investors.

Figure 1 reports the dynamics of net volatility connectedness, tagged with significant events or economic/financial crises. Overall, the volatility connectedness indices for stocks, oil, bonds, and gold remain relatively stable from the 1940 s to the 1960s. However, increased volatility in the financial market due to the crises leads to a rise in the spillovers and thus intensifies the cross-asset linkages. As shown in the figure, the net connectedness of stock market stays negative until the recent global financial crisis, reaching as high as $22 \%$ during the Great Recession ${ }^{4}$. In this episode, stock market acts as a net receiver of volatility shocks that largely subsumes the information about economic and financial instability. Nevertheless, the net volatility connectedness of stocks has changed dramatically since 2008 , switching from a net volatility receiver to a net transmitter to all other assets. In contrast with stock market, bond market shows a rather different pattern of net volatility connectedness. For example, bond market is a net volatility transmitter during most of the periods before 2008, while it shifts from a net transmitter to a net receiver of volatility after 2008. This may be due to the subprime mortgage crisis spread around the world, the increasing investor's negative sentiment which outweighs the sentiment of risk aversion, and thus the role of bond market in asset allocation has shifted.

Furthermore, the role of gold in volatility spillovers (transmission) is reversed during the early 1970s: gold acts as a net transmitter of volatility to all other assets before the early 1970s, while it becomes a net receiver of volatility shocks since 1974. In contrast with the stable net volatility connectedness during the 1940 s to the 1960s, the 1970s witness significant changes. This transformation can be attributable to the collapse of the Bretton Woods system in 1973 along with the cancellation of the dollar's convertibility into gold in 1971. Before the 1970s, gold was acted as the basis of monetary system by linking currency at a fixed rate ${ }^{4}$ The Great Recession was the most severe economic recession in the United States since the Great Depression of the 1930s. It began with the U.S. stock market crash of 1929, economists and historians often cite the Great Recession as the most catastrophic economic event of the 20th century. 
NET Stock

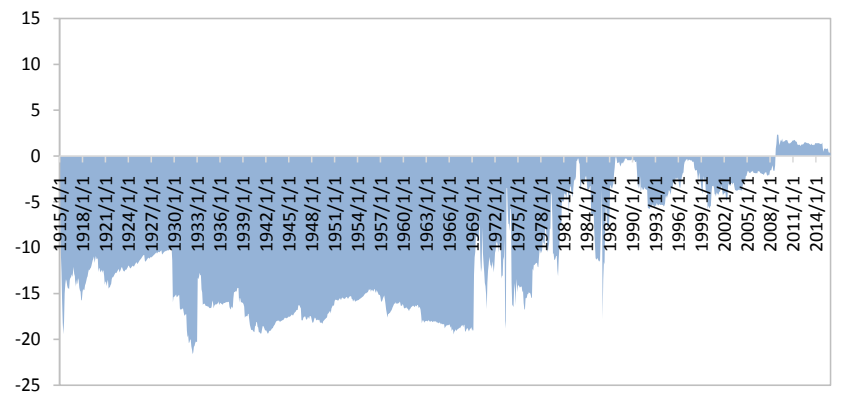

(a)

NET Gold

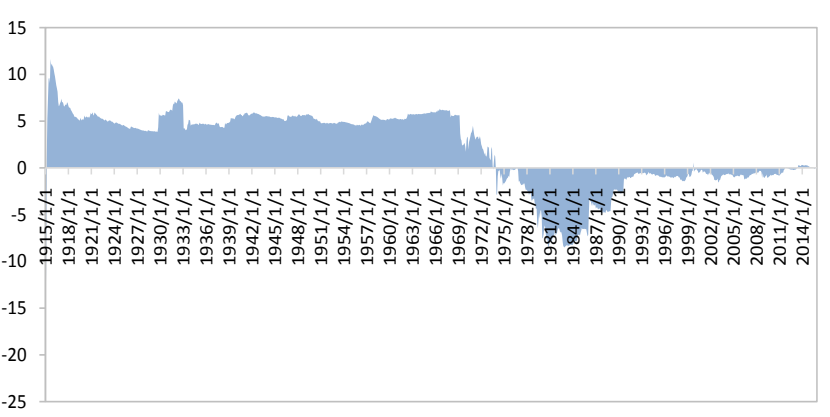

(c)
NET Oil

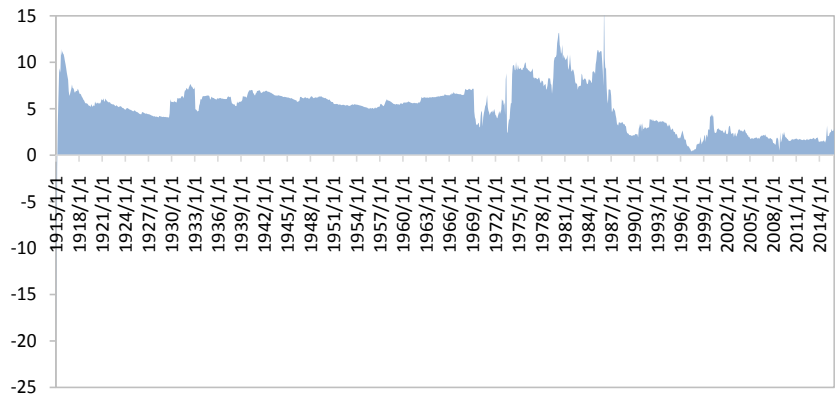

(b)

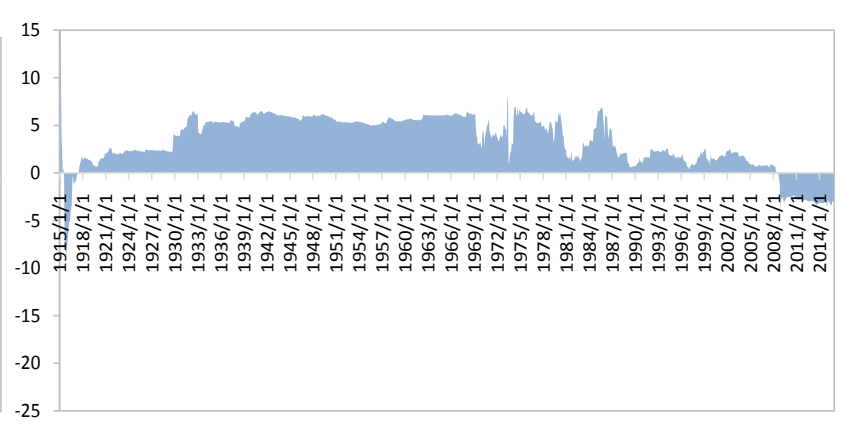

(d)

Figure 1. Net total directional connectedness of four assets. Notes: The figure presents the net directional connectedness of volatility of four assets. The net directional connectedness from all variables $j$ to variable $i$ is the difference between directional volatility spillovers to others and from others: $C_{i, t}^{g}(h)=C_{i \rightarrow j}^{g}(h)-C_{i \leftarrow j, t}^{g}(h)$.

under the Bretton Woods system. The movement of gold prices was mainly determined by its supply and demand, forming an automatic price-stabilizing mechanism (Barro, 2006). However, this mechanism was no longer valid after the collapse and thus volatility connectedness between gold and all other assets fluctuated substantially over time. Sincethen, the role of gold is mainly perceived by investors as a hedge in the periods of market turmoil (Baur \& McDermott, 2010).

Regarding crude oil, the positive net connectedness throughout the sample period indicates that it is a net transmitter of volatility and there are strong spillovers from oil to other assets in the long-term perspective. Interestingly, this is remarkable during the energy crisis from the 1970s to the early 1980s while that of stock market changes from $-15 \%$ to $3 \%$ during 1974 to 1983 , which is in accordance with the US economic recoveries in 1983. During this episode, soaring oil prices led to cost-push inflation, exerting substantially negative influences on firm profits and thus stock market (Zaleski, 1992; Alpanda \& Peralta-Alva, 2010). In 1997, the net volatility spillovers of crude oil reduce to nearly zero. The decline in oil market volatility connectedness was mainly a result of the sudden drop in crude oil demand and thus its prices during the Asian financial crisis.

We also present the net pairwise directional volatility connectedness between all possible pairs of assets in Figure 2. In general, gold is the most isolated asset 
Net Bond - Gold

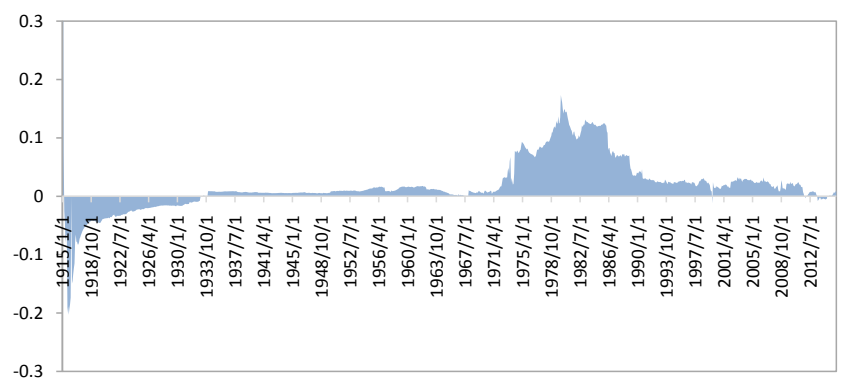

(a)

Net Oil - Gold

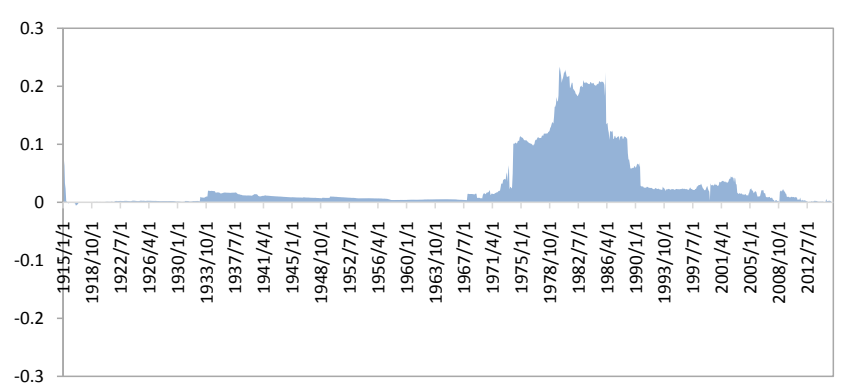

(c)

Net Stock- Bond

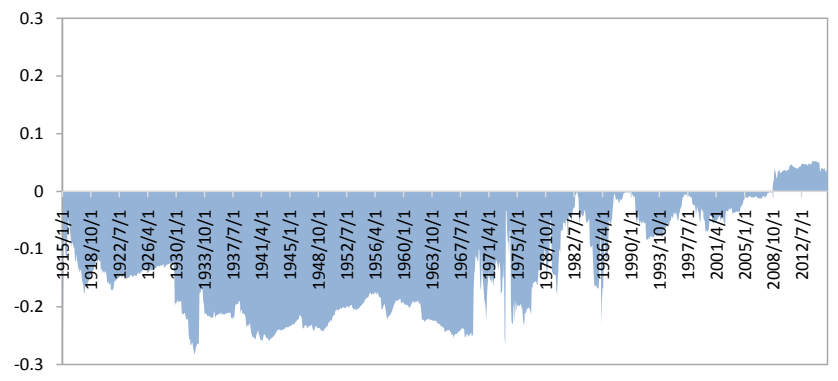

(e)
Net Bond - Oil

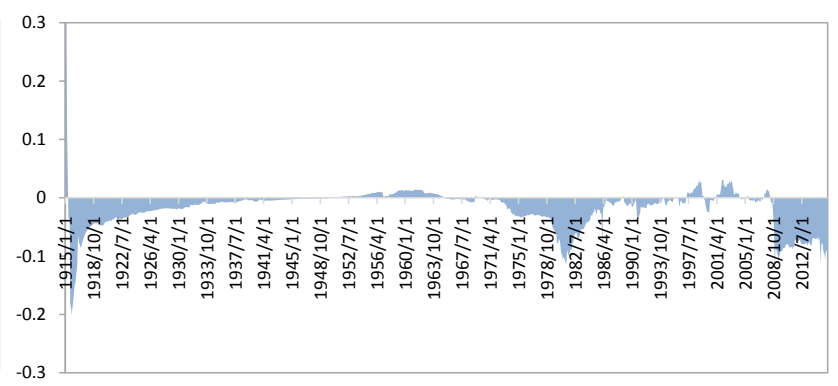

(b)

Net Stock- Gold

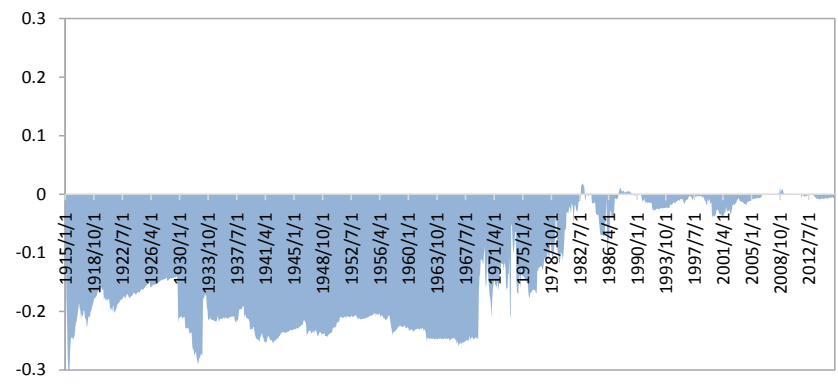

(d)

Net Stock- Oil

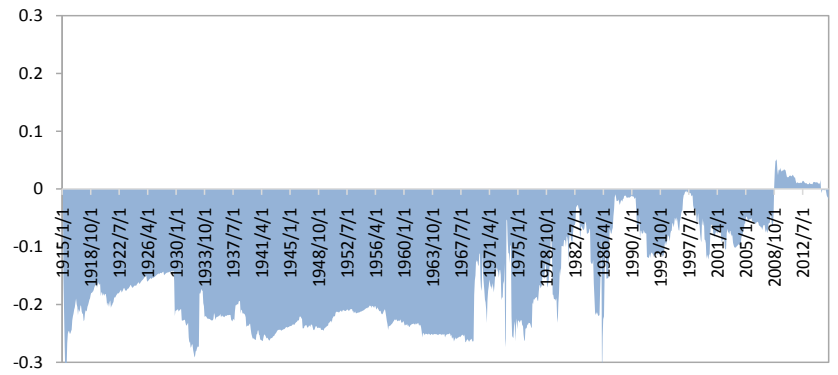

(f)

Figure 2. Net pairwise directional connectedness of assets. Notes: The figure reports the net pairwise directional connectedness index (NPDC) of four assets. The net pairwise volatility spillover between asset $i$ and $j$ is the difference between the volatility shocks transmitted from asset $i$ to asset $j$ and those from asset $j$ to asset $i$, i.e., $\frac{\tilde{\varphi}_{j i, t}^{g}(h)-\tilde{\varphi}_{i j, t}^{g}(h)}{N} \times 100$.

except episodically receiving the volatility spillovers from bonds and oil markets before 1971. This coincides with the cancellation of convertibility of US dollars into gold in 1971 which may have driven sudden changes in the volatility spillovers. Unlike gold, stock is generally the most connected asset with receiving the majority of volatility shocks from all other assets. Further, the role of stock market in the time-variation in net volatility connectedness is reversed during the global financial crisis in 2008: it becomes the net transmitter of shocks to bonds and oil since the crisis, while it acts as the net receiver of volatility from bonds and oil before the crisis. The result shows that since August 2007, the stock market volatility has reflected the dynamics of the sub-prime crisis quite well. As the sub-prime crisis intensified, so too did the stock volatility spillovers, 
with particularly important spillovers from the stock market to bond and oilmarkets taking place in 2008, which is consistent with the findings of (Diebold \& Yilmaz, 2012) of the reversal in the stock. Overall, the pattern of volatility spillovers demonstrates a closer link between stocks and all other assets in a long-term perspective.

\section{Conclusion}

In this paper, we employ the framework of (Antonakakis \& Gabauer, 2017) to study the nature of the volatility transmission among stocks, bonds, oil and gold over the past 100 years. Our empirical findings indicate that volatility spillovers and asset linkages vary considerably over time. Using a century-long historical data (1915-2015), we find that crude oil is a net volatility transmitter during the past 100 years, whereas gold acts as a net volatility receiver only after the 1970s. Moreover, in general, stock is the most connected asset with receiving the majority of volatility shocks from all other assets while switches to a volatility transmitter since 2008. When examining the nature of the cross-asset transmission of volatility, we find that significant change in the volatility connectedness is closely related to the heightened uncertain economic and financial conditions, including economic/energy crisis and the collapse of the Bretton Woods system. The transmission path of net pairwise directional volatility spillover differs greatly within the stagflation and the global financial crisis of 2008. Our analysis is useful to characterize significant transitions of volatility connectedness of asset markets and uncover its underlying linkage with extreme events.

We use time-varying methods to study asset markets, but we are not the first to consider issues related to volatility spillovers. As an extension, alternative volatility measures can be employed instead of return to study dynamic volatility spillovers. In order to extract conditional volatility, future research could use multivariate GARCH methodologies, e.g. the DCC-MGARCH model. Also, future research could make a research on the determinants of dynamic return and volatility spillovers. Finally, the future study can construct a network connectedness across these asset markets to assist policymakers in protecting against contagion risk and fostering market stability.

\section{Acknowledgements}

The author would like to thank the editors and the anonymous reviewer for their valuable comments and suggestions on this paper. The usual disclaimer applies.

\section{Conflicts of Interest}

The author declares no conflicts of interest regarding the publication of this paper.

\section{References}

Alpanda, S., \& Peralta-Alva, A. (2010). Oil Crisis, Energy-Saving Technological Change 
and the Stock Market Crash of 1973-74. Review of Economic Dynamics, 13, 824-842. https://doi.org/10.1016/j.red.2010.04.003

Andrada-Félix, J., Fernandez-Perez, A., \& Sosvilla-Rivero, S. (2018). Fear Connectedness among Asset Classes. Applied Economics, 50, 4234-4249. https://doi.org/10.1080/00036846.2018.1441521

Antonakakis, N., \& Gabauer, D. (2017). Refined Measures of Dynamic Connectedness Based on TVP-VAR. MPRA Pap. No. 782782.

Barro, R. J. (2006). Money and the Price Level under the Gold Standard. The Economic Journal, 89, 13-33. https://doi.org/10.2307/2231404

Baruník, J., Kočenda, E., \& Vácha, L. (2016). Asymmetric Connectedness on the U.S. Stock Market: Bad and Good Volatility Spillovers. Journal of Financial Markets, 27, 55-78. https://doi.org/10.1016/j.finmar.2015.09.003

Basher, S. A., Haug, A. A., \& Sadorsky, P. (2012). Oil Prices, Exchange Rates and Emerging Stock Markets. Energy Economics, 34, 227-240. https://doi.org/10.1016/j.eneco.2011.10.005

Baur, D. G., \& McDermott, T. K. (2010). Is Gold a Safe Haven? International Evidence. https://doi.org/10.2139/ssrn.1516838

Büyükşahin, B., \& Robe, M. A. (2014). Speculators, Commodities and Cross-Market Linkages. Journal of International Money and Finance, 42, 38-70.

https://doi.org/10.1016/j.jimonfin.2013.08.004

Cappiello, L., Engle, R. F., \& Sheppard, K. (2006). Asymmetric Dynamics in the Correlations of Global Equity and Bond Returns. Journal of Financial Economics, 4, 537-572. https://doi.org/10.1093/jjfinec/nbl005

Chen, P. (2018). Understanding International Stock Market Comovements: A Comparison of Developed and Emerging Markets. International Review of Economics \& Finance, 56, 451-464. https://doi.org/10.1016/j.iref.2017.12.004

Connolly, R., Stivers, C., \& Sun, L. (2005). Stock Market Uncertainty and the Stock-Bond Return Relation. Journal of Financial and Quantitative Analysis, 40, 161-194. https://doi.org/10.1017/S0022109000001782

Diebold, F. X., \& Yilmaz, K. (2012). Better to Give than to Receive: Predictive Directional Measurement of Volatility Spillovers. International Journal of Forecasting, 28, 57-66. https://doi.org/10.1016/j.ijforecast.2011.02.006

Fleming, J., Kirby, C., \& Ostdiek, B. (1998). Information and Volatility Linkages in the Stock, Bond, and Money Markets. Journal of Financial Economics, 49, 111-137. https://doi.org/10.1016/S0304-405X(98)00019-1

Foroni, C., Guérin, P., \& Marcellino, M. (2017). Explaining the Time-Varying Effects of Oil Market Shocks on US Stock Returns. Economics Letters, 155, 84-88. https://doi.org/10.1016/j.econlet.2017.03.017

Grobys, K. (2015). Are Volatility Spillovers between Currency and Equity Market Driven by Economic States? Evidence from the US Economy. Economics Letters, 127, 72-75. https://doi.org/10.1016/j.econlet.2014.12.034

Hartmann, P., Straetmans, S., \& De Vries, C.G. (2004). Asset Market Linkages in Crisis Periods. The Review of Economics and Statistics, 86, 313-326. https://doi.org/10.1162/003465304323023831

Kilian, L., \& Park, C. (2009). The Impact of Oil Price Shocks on the U.S. Stock Market. International Economic Review (Philadelphia), 50, 1267-1287. https://doi.org/10.1111/j.1468-2354.2009.00568.x

Koop, G., Pesaran, M. H., \& Potter, S. M. (1996). Impulse Response Analysis in Nonlinear 
Multivariate Models. Journal of Economics, 74, 119-147.

https://doi.org/10.1016/0304-4076(95)01753-4

Pesaran, H. H., \& Shin, Y. (1998). Generalized Impulse Response Analysis in Linear Multivariate Models. Economics Letters, 58, 17-29.

https://doi.org/10.1016/S0165-1765(97)00214-0

Phylaktis, K., \& Ravazzolo, F. (2005). Stock Prices and Exchange Rate Dynamics. Journal of International Money and Finance, 24, 1031-1053.

https://doi.org/10.1016/j.jimonfin.2005.08.001

Yang, J., Zhou, Y., \& Wang, Z. (2009). The Stock-Bond Correlation and Macroeconomic Conditions: One and a Half Centuries of Evidence. Journal of Banking \& Finance, 33, 670-680. https://doi.org/10.1016/j.jbankfin.2008.11.010

Yang, Z., \& Zhou, Y. (2016). Quantitative Easing and Volatility Spillovers across Countries and Asset Classes. Management Science, 63, 333-354.

https://doi.org/10.1287/mnsc.2015.2305

Zaleski, P. A. (1992). Industry Concentration and the Transmission of Cost-Push Inflation: Evidence from the 1974 OPEC Oil Crisis. Journal of Economics and Business, 44, 135-141. https://doi.org/10.1016/0148-6195(92)90012-Y

Zaremba, A., Kambouris, G. D., \& Karathanasopoulos, A. (2019). Two Centuries of Global Financial Market Integration: Equities, Government Bonds, Treasury Bills, and Currencies. Economics Letters, 182, 26-29. https://doi.org/10.1016/j.econlet.2019.05.043 